\title{
Uma categorização analítica para estudo e comparação de práticas clínicas em distintas racionalidades médicas
}

I ${ }^{1}$ Charles Dalcanale Tesser, ${ }^{2}$ Madel Therezinha Luz I

Resumo: Este artigo apresenta uma categorização analítica de encontros clínicos para investigações comparativas de práticas clínicas em diferentes sistemas médicos, de forma equidistante deles. Ela foi concebida como um tipo ideal weberiano e norteada pela dinâmica da eficácia simbólica proposta por Lévi-Strauss. Postularamse seis movimentos como constituintes dos encontros clínicos em geral: (1) acolhida do usuário; (2) escuta das demandas; (3) investigação do problema; (4) elaboração da interpretação diagnóstica; (5) socialização do diagnóstico; e (6) elaboração, consensuação e execução da terapêutica. Tais movimentos podem ser associados com as dimensôes das racionalidades médicas, conforme Madel Luz (cosmologia, doutrina, fisiologia, morfologia, sistemas diagnóstico e terapêutico), e permitem descrição, análise e comparação de práticas clínicas norteadas por uma racionalidade médica. Assim, este instrumento analítico pode facilitar a investigação e compreensão das abordagens de distintos sistemas médicos, contribuindo para a compreensão e comparabilidade das suas práticas clínicas e de sua eficácia.

> Palavras-chave: medicina tradicional; medicina alternativa; metodologia.

\author{
1 Departamento de Saúde Pública, \\ Universidade Federal de Santa \\ Catarina. Florianópolis-SC, Brasil \\ (charles.tesser@ufsc.br). ORCID: \\ 0000-0003-0650-8289 \\ 2 Programa de Pós-Graduação \\ em Saúde Coletiva, Universidade \\ Federal do Rio Grande do \\ Sul. Porto Alegre-RS, Brasil \\ (madelluz@uol.com.br). ORCID: \\ 0000-0001-8253-592X
}

Recebido em: 11/08/2015 Aprovado em: 08/09/2017 Revisado em: 26/02/2018 


\section{Introdução}

$\mathrm{O}$ interesse social e acadêmico no ocidente por formas de cuidado agrupadas sob a etiqueta de medicinas tradicionais e complementares vem aumentando nas ultimas décadas (OMS, 2013; LUZ, 2005; BARROS, 2008; NASCIMENTO; NOGUEIRA, 2013). Madel Luz (LUZ; CAMARGO Jr., 1997; LUZ; BARROS, 2012) desenvolveu a categoria analítica 'racionalidade médica' para investigar e comparar sistemas médicos complexos, vários incluídos nessa etiqueta. Um sistema de cuidado/cura foi considerado uma 'racionalidade médica' (doravante abreviada para RM) se seis dimensóes constituintes, coerentes e articuladas entre si puderem ser nele identificadas e descritas: uma doutrina médica (concepçóes e explicaçôes gerais sobre vida, saúde, adoecimento e cura), uma dinâmica vital (equivalente à fisiologia, na biomedicina), uma morfologia (ou anatomia, na biociência), um sistema diagnóstico e um sistema terapêutico. Estas cinco dimensôes são permeadas por uma cosmovisão ou cosmologia, como sexta dimensão subjacente, conforme ilustrado na Figura 1. Através dessa categoria, foi possível estudar e reconhecer como RMs a biomedicina, a homeopatia, a medicina chinesa tradicional, a medicina antroposófica e a medicina ayurvédica (LUZ; BARROS, 2012; NASCIMENTO et al., 2013).

\section{Figurra 1. Dimensóes da categoria "racionalidade médica"}

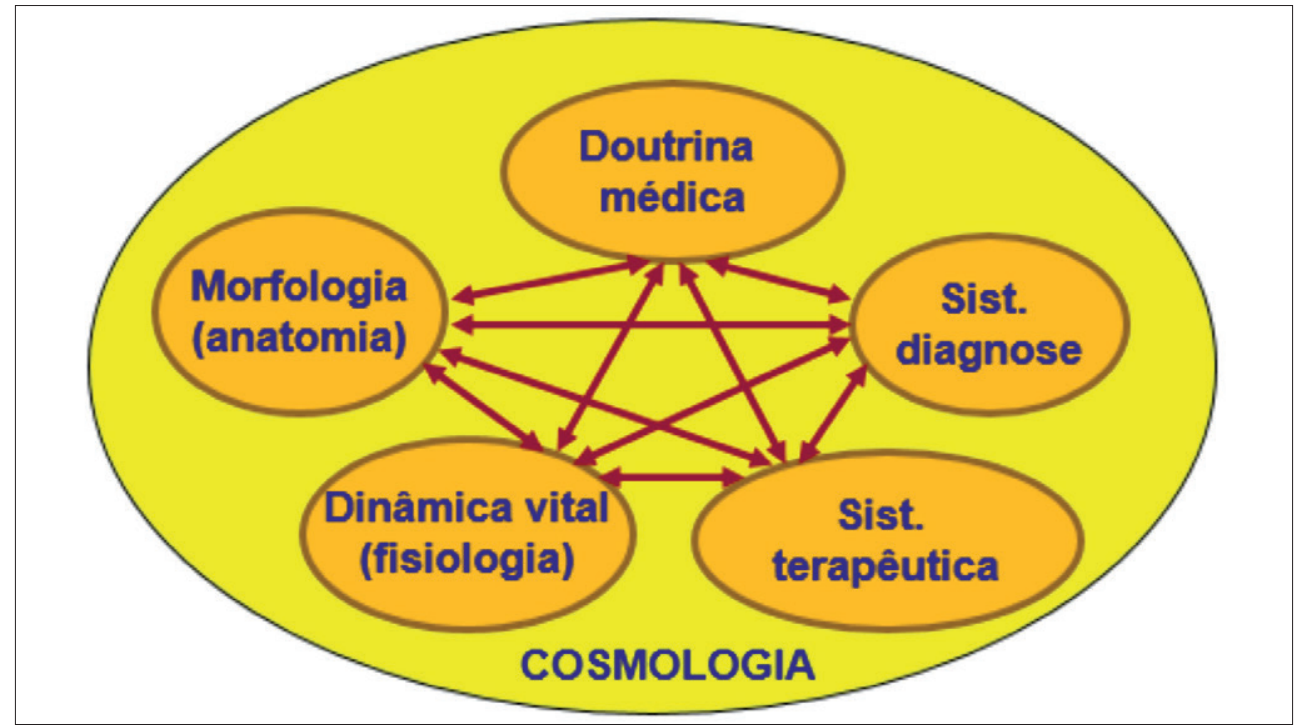

Fonte: elaborada pelos autores. 
O ponto potencialmente mais fértil de comunicação ou diálogo entre sistemas médicos diferentes é a dimensão da terapêutica, envolvendo práticas de cuidado (ALMEIDA, 2002). Nela, os compromissos éticos dos curadores os aproximam, contrariamente às dimensóes doutrinárias, "teóricas" e cosmológicas, em que as RMs tendem a divergir (LUZ, 2000).

O objetivo deste artigo é propor uma categorização da dinâmica de um encontro clínico inserido em ou orientado por uma RM. Tal categorização foi concebida como instrumento analítico para pesquisa, análise e discussão de encontros clínicos em ambiente ambulatorial comunitário. Pretendemos, no âmbito teórico, contribuir para investigaçóes de atos clínicos, independentemente da RM envolvida, que facilitem a sua compreensão e comparação. O foco, portanto, é na escala microssocial da ação clínica, sem desconsiderar os saberes subjacentes e as conexôes sociotécnicas envolvidas (LATOUR, 2009; 2012; MORAES, 2004).

No âmbito empírico, almejamos instrumentalizar investigaçôes comparativas de práticas clínicas: desde vários atendimentos do mesmo terapeuta, passando por terapeutas diferentes (médicos, por exemplo) ou especialidades dentro de uma RM, até a comparação entre RMs diversas em ação. Outra utilidade é pedagógica: o ensino médico foi o contexto indutor da construção da categorização, facilitadora de discussôes didáticas de práticas clínicas reais ou simuladas nos últimos seis anos.

Foi construído um "tipo ideal" de ato clínico, com características consideradas típicas ou tendenciais desse fenômeno (LUZ, 2000; QUINTANEIRO et al., 2003, WEBER, 2004). Uma estrutura geral derivada da antropologia forneceu sentido e dinâmica ao construto, a partir da proposta de Lévi-Strauss (1976) sobre a 'eficácia simbólica', que visava explicar o êxito relativo dos procedimentos de curadores indígenas. Sem discuti-la detalhadamente, sintetizamo-la a seguir.

\section{Sobre a eficácia simbólica}

Lévi-Strauss (1976) discutiu como "os símbolos têm o poder de atuar sobre o mundo material” (BONET, 2012, p. 101). Haveria uma analogia ou homologia entre estruturas simbólicas e corporais e uma "propriedade indutora" de como certos procedimentos em situaçôes determinadas provocam mundança em uma dimensão (corporal, orgânica) induzida pela intervenção em outra (simbólica) (p. 103-4). O conceito foi muito utilizado e gerou diversas abordagens (TAVARES; 
BASSI, 2012). Em geral, médicos e cirurgiôes concordariam que há uma dimensão simbólica nas suas práticas e tratamentos. Apenas ela seria supostamente residual: o grosso de sua eficácia assentar-se-ia no efeito material específico do procedimento ou medicamento (BONET, 2012).

Independentemente dessa questão controversa, há um crescente apelo simultaneamente ético e técnico para revalorização da dimensão simbólica na biomedicina, ligada à relação terapeuta-usuário: a antiga reivindicação de consideração da pessoa como um todo; o discurso institucional da "humanização" (BRASIL, 2004); o reconhecimento de que o efeito placebo ou inespecífico é importante (PRICE et al., 2008; BYSTAD et al., 2015); a valorização crescente das "habilidades de comunicação" (PENDLETON et al., 2007) na formação e prática médicas; reformas do método clínico centrando-o na pessoa (STEWART, 2010).

Mesmo que a visão dicotômica entre eficácia inespecífica e eficácia específica seja pouco sustentável, assim como a equivalência entre eficácia simbólica e efeito inespecífico, ambas nos são úteis ao permitirem uma aproximação inicial do tema, de modo crítico, sem rejeitar nem aderir às noçóes biomédicas, mas dialogando com elas.

Lévi-Strauss (1976) destacou aspectos do que chamou de eficácia simbólica. O primeiro é que o adoecimento é um evento individual e social, compartilhado com familiares, que influenciam a reação emocional, as crenças, os cuidados e o momento de procurar ajuda especializada: há a construção de expectativas e projeção de legitimidade e de poderes no curador procurado, reconhecido como tal, por méritos individuais, pelo saber/técnica que domina ou por ambos. $\mathrm{O}$ segundo aspecto é que o curador é um membro de uma tradição ou corporação de legítimos praticantes de um saber/técnica de cura, reconhecido como tal pela sociedade e por seus pares. O terceiro aspecto é a conjunção harmônica dos dois anteriores (pressupostos como existentes), entendida como uma confluência de papéis, expectativas, compartilhamento de crenças gerais sobre o mundo, a doença e a cura. Resultaria da interação harmônica destes aspectos a produção da eficácia simbólica, sintetizada a seguir.

O doente leva ao curador suas angústias, dores e sintomas. Este as acolhe, legitima, integra e reinterpreta conforme seu sistema de saber/técnica, oferecendo sua interpretação. $\mathrm{O}$ doente, via de regra, aceita a interpretação, acreditando no saber especializado do curador, dado haver nela elementos convergentes com suas 
crenças e modelos explicativos. O oferecimento da interpretação envolve e engaja o doente, induz nele uma reorganização simbólica e emocional (acalma medos, angústias e ansiedades) e reorganiza os sentidos do vivido, preparando o tratamento, coerentemente com a interpretação. $O$ processo precedente viabiliza e inicia a mobilização de processos simbólicos, afetivo-emocionais e fisiológicos, intensificados e consumados na realização do tratamento. $\mathrm{O}$ conjunto acima seria responsável pela cura, via mobilização simbólica da "fisiologia" do doente.

A redução das terapêuticas de outras sociedades/culturas a rituais com efeito placebo potente é um preconceito etnocêntrico hoje insustentável, inclusive a partir da biomedicina: técnicas várias ali envolvidas têm efeitos específicos, além de inespecíficos, como as plantas medicinais e a acupuntura (esta última antes considerada ritualística e mística [NASCIMENTO, 2006]). Em todo caso, é consensual que a eficácia inespecífica dos tratamentos é importante e age sinergicamente com a sua "parte específica". Além disso, estudos mostraram a grande dificuldade ou mesmo impossibilidade de isolar uma da outra (KAPTCHUK et al., 2001).

Mesmo em sociedades ocidentais urbanizadas altamente estratificadas, com culturas sincréticas variadas concernindo à saúde e ao adoecimento, como o Brasil (RIBEIRO, 1995), a eficácia simbólica (associada ao efeito inespecífico) é significativa e deve ser buscada em qualquer cuidado especializado. Hoje, em que pese o compartilhamento simbólico entre doente e curador ser menor e as possibilidades de realização dos tratamentos serem diversificadas (às vezes, inclusive nulas), e por causa desses fatores, o efeito inespecífico permanece uma busca comum aos curadores das várias RMs, sem o qual se perde grande parte da eficácia geral em muitos casos (DI BLASI et al., 2001; BYSTAD et al., 2015; DECETY; FOTOPOULOU, 2014; SIMS; TSAI, 2015).

\section{A dinâmica de um encontro clínico e seus componentes}

A partir da generalidade e transculturalidade da dinâmica acima sintetizada, envolvida na produção da eficácia simbólica, construímos um tipo ideal de ato clínico: o fluxo da ação clínica pode ser decomposto, para fins de análise, em seis movimentos componentes de um ato clínico, esquematizados na Figura 2, a seguir apresentados. 
Figura 2. Dinâmica dos encontros clínicos

\begin{tabular}{|c|c|c|}
\hline Protagonismo & Movimentos componentes da ação & $\begin{array}{c}\text { Fluxo da } \\
\text { ação }\end{array}$ \\
\hline \multirow{2}{*}{ Doente } & 1-Acolhida & \\
\hline & 2- Escuta & \\
\hline dor & 3-Investigação & \\
\hline & 4- Elaboração da interpretação diagnóstica & \\
\hline \multirow{2}{*}{ Curador + Doente } & 5-Socialização do diagnóstico & \\
\hline & 6- Elaboração/execução do tratamento & \\
\hline
\end{tabular}

Fonte: elaborada pelos autores.

Embora os movimentos ocorram em um fluxo temporal, eles formam um todo holográfico, sendo parcialmente sobrepostos. Há protagonismos preponderantes, sendo nos dois primeiros movimentos mais do doente; nos dois seguintes, do curador - designação genérica para o terapeuta de qualquer RM; e nos dois últimos, geralmente o protagonismo parte do curador e envolve mais ou menos o doente, conforme a situação e a técnica terapêutica.

\section{Acolhida}

No geral, o encontro clínico inicia com a demanda de um doente, numa situação em que a sua competência autônoma fracassou, o problema não melhorou, persistiu e ou agravou-se. Por isso, há comumente insegurança, medos e preocupaçôes, além do sofrimento vivido, que tendem a agravar o quadro, com dúvidas e angústia quanto à natureza do problema. $\mathrm{O}$ que identifica este primeiro movimento, da parte do curador, é uma atitude de aceitação e acolhida afetiva dessa demanda, dos problemas e dúvidas trazidos, que inaugura a relação de cura ou de cuidado, caracterizada por um pacto ético ancestral de solidariedade e ajuda, em que confiança, respeito, intimidade, não julgamento e privacidade estão envolvidos. Este primeiro movimento é em geral curto e nele a comunicação não verbal e visual é importante, embora haja usualmente algum cumprimento verbal seguido de uma questão aberta estimuladora do relato do usuário, que inicia a transição para o segundo movimento. 
À primeira vista, parece haver convergência entre RMs diferentes quanto à acolhida e sua importância, sendo dispensável neste momento discussão específica sobre diferenças a esse respeito, que deverão manifestar-se conforme as especificidades de cada RM e ou cada terapeuta.

\section{Escuta}

Acolhido o usuário, o curador o convida a relatar os motivos de sua procura, os problemas que o afligem. Há grande interpenetração entre a acolhida e a escuta, pois uma boa e atenta escuta significa o prolongamento, o crescimento e a consolidação da acolhida. O protagonismo nestes dois primeiros movimentos fica com o usuário, mas o curador também participa. Ele faz muito através do escutar atento: valoriza, respeita, aceita e se conecta emocionalmente com o usuário. Constrói a relação de cura ao se abrir para que as informaçôes fluam livremente, o que nem sempre ocorre facilmente para os doentes, muitas vezes imersos em sofrimentos, vergonhas, culpas, medos etc.

As RMs e/ou os curadores individualmente têm formas distintas de manejo desses primeiros dois componentes do ato clínico, mas podemos afirmar que eles fazem parte de qualquer encontro clínico. Na homeopatia, por exemplo, a escuta é ainda mais amplificada e enfatizada (SALLES, 2002; ROSEMBAUM, 2006).

\section{Investigação}

Dificilmente um curador fica satisfeito apenas com o relato espontâneo do usuário, uma versão leiga baseada no que o doente percebe como associado ao seu adoecimento. Por ser um especialista, o terapeuta quer saber mais, vai complementar e aperfeiçoar o relato espontâneo com questóes, observaçôes e exames, orientado pelos saberes e técnicas que domina.

A investigação começou na acolhida, desenvolveu-se na escuta e vai chegar ao seu ápice nas perguntas que o curador fará e nos exames que realizará, que em geral envolvem o corpo do doente e podem ser de diversas naturezas. Em grande parte, a investigação é feita verbalmente. Além disso, os curadores observam o doente, em aspectos gerais e específicos, palpam e pressionam seu corpo, escutam ruídos derivados do corpo, avaliam às vezes as excreçôes e secreçôes, investigam fatores ou aspectos sutis, por vezes impalpáveis e invisíveis, visando acessar os processos envolvidos no adoecimento ou pistas sobre os mesmos. 
$\mathrm{Na}$ investigação, o curador é o principal protagonista. Cada RM, através de seu sistema diagnóstico, orientará técnicas e saberes propedêuticos (articulados com seus saberes doutrinários, de dinâmica vital e morfologia), que o terapeuta exercitará com o objetivo de elucidar a natureza do adoecimento do doente.

\section{Elaboração da interpretação diagnóstica}

Durante a escuta e a investigação, o curador elabora progressivamente uma interpretação do adoecimento, que em algum momento estará suficientemente concluída, e em que uma grande dose de intuição, no sentido dado ao termo por Bergson (GUIMARÁES, 2005), tem papel relevante, inevitável e desejável. Este movimento não é bem localizado no tempo, mas um processo que se constrói ao longo dos primeiros movimentos e culmina quando o curador julga ser suficiente a interpretação diagnóstica construída.

Aqui, o protagonismo do curador é total e sua responsabilidade quanto à produção da interpretação do quadro trazido pelo doente é notável. Não há protocolo ou técnica objetivante (exame diagnóstico) que modifique a natureza desta tarefa complexa, que remete o curador ao seu aprendizado, sua prática pregressa, sua RM. Ele pode discutir com seus pares ou seguir um protocolo, mas isso não modifica a natureza da responsabilidade ética e epistemológica da produção da interpretação.

Dada a pluralidade das RMs, um mesmo 'caso' potencialmente admitirá mais de uma interpretação. Os saberes das várias RMs, exercitados pelos seus curadores, entram em jogo de modo a produzir a diversidade de interpretaçóes (e tratamentos) das RMs que persistem no mundo. Tais saberes são limitados e produzem verdades ou interpretaçóes parciais sobre os adoecimentos, chamadas por Tesser (2013) de interpretaçôes paradigmáticas. Elas orientarão práticas mais ou menos convergentes entre si, mais ou menos eficazes, do ponto de vista de uma RM (ou do curador) e do ponto de vista do usuário.

A interpretação ressignificará o quadro trazido pelo doente, dando-lhe sentido e significado atrelados aos saberes, valores e técnicas do curador e sua RM. Por vezes, dentro de uma mesma racionalidade várias interpretaçôes podem ser produzidas com efetividade (nos tratamentos delas decorrentes), conforme as situaçôes e os terapeutas. 


\section{Socialização do diagnóstico}

Levados a bom termo os movimentos anteriores, o curador geralmente toma a iniciativa de oferecer sua interpretação. Para que esta explique o adoecimento e reorganize as emoçóes do usuário, preparando-o para o tratamento que virá, ela deve fazer algum sentido para o doente, envolvendo elementos mais ou menos concebidos no seu universo cultural. Caberá ao par curador-doente entrar num acordo sobre a natureza do problema, para o qual, obviamente, a interpretação especializada e sua socialização terão papéis decisivos.

Tal condição é facilmente cumprida em ambientes em que o curador vive vida similar à do doente (social e culturalmente), ou quando há grande semelhança cultural entre os dois. No mundo globalizado urbanizado, isso não está garantido e há dificuldades adicionais, variáveis.

Quanto a este movimento, curadores das várias RMs ou tradiçôes de cura têm necessidade de uma socialização mínima suficiente de suas interpretaçóes, dependendo dos tipos de tratamento e das tradiçóes envolvidas, e variando amplamente em estilos e formas de manejo da situação.

\section{Elaboração e execução do tratamento}

A construção e execução do plano terapêutico é a decorrência esperada do encontro clínico, pois a interpretação produzida não tem outro compromisso ético e objetivo prático que a produção de açóes terapêuticas. Trata-se de um processo teleológico, cuja finalidade é o cuidado/cura do doente (ALMEIDA, 2002).

$\mathrm{O}$ teor de verdade/confiabilidade das interpretaçóes, sempre maximamente desejado porque associado à eficácia terapêutica, não é absoluto. As verdades das interpretaçóes e as potências dos tratamentos produzidos pelos curadores estão atreladas aos 'paradigmas' (KUHN, 2013) ou "estilos de pensamento" (FLECK, 2010) ou RMs (LUZ; BARROS, 2012) orientadores do atendimento, equivalentes entre si para efeito desta discussão. Logo, esse teor de verdade é relativo e dependente das características e do estado da arte da RM envolvida e da expertise do curador, sendo assim duplamente limitado, o que trará consequências importantes para a discussão (posterior) sobre a eficácia dos tratamentos.

Supondo socializada com êxito suficiente a interpretação, o curador oferece seu plano de manejo do problema, esclarecendo o significado das açôes terapêuticas. 
Estas últimas variarão conforme as técnicas dominadas pelo curador e podem implicar protagonismo variado tanto do usuário (situaçôes que envolvem realização de dietas, práticas corporais ou outras e/ou uso de remédios no seu dia a dia), quanto do curador (situaçôes em que o curador aplica, de uma forma ou de outra, a terapêutica diretamente no usuário). A operacionalização da terapêutica terá que ser pactuada, o que envolve uma parceria e consenso na construção do plano.

A elaboração do plano de manejo de regra inicia na elaboração e continua na socialização da interpretação, uma vez que há comumente significativa articulação das possiblidades interpretativas com as terapêuticas nas RMs, embora isso varie entre elas e com o tipo de problema. Vão variar os tempos, prazos e formas de aplicação do tratamento, desde curtos, imediatos e únicos até tratamentos longos, lentos e em aplicaçóes sucessivas. Nos casos de longo prazo ou repetida aplicação presencial, o ato clínico, mais ou menos abreviado, repetir-se-á nos encontros destinados ao tratamento.

Esse conjunto de movimentos constitutivos dos encontros clínicos, praticados com coerência, harmonia e expertise (conforme as RM envolvidas), é responsável tanto pela eficácia simbólica (ou inespecífica), quanto pela eficácia específica da terapêutica. Através desta categorização, o ato clínico pode ser descrito, compreendido, avaliado e comparado. Também é relevante a descrição da mobilização de instrumentos, materiais e serviços de várias naturezas (ou seja, de intermediários e mediadores), que as técnicas diagnósticas e terapêuticas articularão, consoante suas RMs, para tratamento, prevenção e promoção, o que pode permitir um vislumbre da construção ou adoção de uma rede sociotécnica (conforme LATOUR, 2009; 2012) mais ou menos estabilizada de cuidados.

\section{O encontro clínico na biomedicina: breve comentário}

Como aplicação inicial da nossa categorização, esboçamos uma aproximação dos encontros clínicos na RM biomédica, enfatizando alguns de seus aspectos críticos, dada sua ampla hegemonia institucional. Sabemos da interveniência de múltiplas forças poderosas nos movimentos acima postulados dos encontros clínicos no Brasil nos serviços públicos e privados. Em muitos locais, elas tornam esses movimentos quase ideais, no sentido de descolados da realidade das práticas: consideramos que, até para seu estudo e registro nesses casos, esta categorização pode ser útil. 
Quanto ao fluxo dos movimentos, recomenda-se, por razóes práticas, na biomedicina, que sua ordem seja respeitada. A sequência S-O-A-P (subjetivoobjetivo-análise-plano), utilizada para o registro clínico biomédico, sobretudo na medicina de família e comunidade (QUEIROZ, 2009; MCWHINNEY, 2010), ou a sequência mais clássica, anamnese-exame físico-hipóteses diagnósticas-conduta terapêutica, similares à nossa categorização, são enfatizadas para organizar a interação e otimizar a gestão do tempo nos atendimentos e seu registro.

A acolhida, na biomedicina, em teoria parece comungar da mesma relevância a ela atribuída pelas demais RMs. A escuta também é muito importante: é a melhor fonte de informações do médico ambulatorial para a realização da maior parte das interpretaçóes (PETERSON et al., 1992; SILVERMAN et al., 2016) e orienta (ou deve orientar) a investigação.

Todavia, nas práticas contemporâneas da biomedicina, não é raro que a escuta seja desvalorizada, sobretudo a partir da progressiva adesão às tecnologias objetivantes de produção de informaçôes (bioquímicas, biofísicas e de imagens) sobre o interior do corpo. Para Foucault (2004), este deslocamento se associa à histórica mudança na atenção do médico, no alvorecer da clínica biomédica, do "ouvir" os doentes para o "olhar" o corpo e seu interior, procurando lesôes supostamente responsáveis pelos adoecimentos.

Associado a isso, há uma tendência condutual comum de não deixar espaço para o relato livre, que é rapidamente controlado e dirigido pelo médico (transformando-se num interrogatório), visando delinear uma doença, categoria central na biomedicina (CAMARGO JR., 2003). Há décadas, estudos mostraram que os médicos tendem a serem impacientes na escuta, a abortam frequentemente e direcionam o relato de seus usuários (BECKMAN; FRANKEL, 1984; MARVEL et al. 1999; ROSHAN; RAO, 2000; RHOADES et al., 2001; FRIEDMAN et al., 2009).

Deve ser lembrado que não há mudança no "estado da arte" ou no saber biomédico que justifique as condutas abreviadoras da escuta atenta e empática: a boa técnica clínica biomédica (o "deve ser") continua alicerçada no relato do doente, com a maioria dos diagnósticos médicos sendo elaborados decisivamente através da história clínica (PETERSON et al., 1992; MCDONALD; FEDO, 2009; MALTERUD et al., 2015). Por isso, foi incorporada na literatura sobre o ensino e treinamento da boa técnica clínica a diretriz de privilegiar a escuta da narrativa dos usuários sem interrupçôes (GASK; USHERWOOD, 2002; HAIDET; PATERNITI, 2003; 
SILVERMAN et al., 2016). Principalmente, no início dos encontros clínicos, os primeiros minutos devem ser dedicados exclusivamente à escuta do relato livre do usuário (RABINOWITZ et al., 2004; STEWART et al., 2010).

A investigação, para além do diálogo e do exame físico com instrumentos carregados nos bolsos, envolverá exames complementares, quando necessários, que interrompem o encontro, retomado posteriormente. A sua solicitação deve ser criteriosa, porque se não (o que é muito comum) há significativo potencial de desvio do fluxo do cuidado e de dano ao doente (NORMAN; TESSER, 2009).

Quanto à elaboração da interpretação, destaca-se a responsabilidade epistemológica dos médicos, assolada pela progressiva estandardização dos diagnósticos e tratamentos (DALMASO, 1998; HARRISON; 2009) via algoritmos decisórios, pela ascensão da medicina baseada em evidências (MBE). Esta última nasceu do legítimo anseio de disponibilizar aos clínicos e valorizar os resultados de pesquisas publicadas (saber clínico cientificamente validado), para além do saber clínico empírico subsidiário das opiniôes, tradiçôes e consensos de especialistas.

Todavia, uma vez que o movimento da MBE se legitimou, colocando as revisóes e metanálises de ensaios clínicos no topo da hierarquia das evidências, com poder de instituir condutas diagnósticas e terapêuticas, ela foi em grande parte cooptada pelos interesses comerciais das indústrias farmacêuticas e de equipamentos biomédicos, sendo hoje considerada um movimento em crise (GREENHALGH et al., 2014). Seu poder, inclusive, tem gerado o que Harrison et al. (2002) e Harrison (2009) chamam de 'medicina burocrática', na qual cada vez menos o profissional assume a sua inerente responsabilidade ética-epistemológica na decisão interpretativa e terapêutica, restingindo-se a seguir protocolos instituídos.

Talvez a socialização da elaboração seja um dos momentos mais problemáticos na biomedicina, junto com a terapêutica. Os médicos brasileiros, sobretudo do SUS, vivem, geralmente, uma vida muito díspar da dos seus usuários, devido à excessiva estratificação social do país e a sua multiculturalidade (RIBEIRO, 1995). Assim, a socialização da interpretação carece do que se convencionou chamar "habilidades de comunicação" e "competência cultural". Tanto no início do atendimento (acolhida, escuta e investigação), quanto em seu final (socialização da interpretação e consensuação do projeto terapêutico), há que cuidar com a linguagem utilizada e os sentidos construídos, se estão sendo processados na direção das eficácias simbólica e específica, e não produzindo efeito contrário, comum quando ocorre 
indiferença, frieza, pouco contato verbal e visual, unidirecionalidade e pouca compreensão mútua na comunicação.

São antigos os estudos evidenciando grandes proporçôes de desencontros comunicacionais entre médicos e seus usuários, envolvendo divergência quanto à natureza dos problemas (STARFIELD et al., 1981), desconsideração por grande parte das queixas e distúrbios relatados (STEWART et al., 1979), principalmente dos problemas psicossociais (SCHULBERG et al., 1988). No Brasil, Schraiber (2008) estudou mudanças no trabalho médico e encontrou crise dos vínculos de confiança. Estudos e diretrizes mais recentes corroboram esses problemas e a prioridade para o aperfeiçoamento das habilidades de comunicação dos médicos (CARRIÓ, 2012; SILVERMAN et al., 2016).

Vários fatores provavelmente têm influência significativa nesses problemas comunicacionais, alguns dos quais mencionamos brevemente. A maior parte da fração prática da formação médica ocorre no ambiente hospitalar, que é excepcional, com relações institucionais rigidamente hierárquicas e extremadas delegaçôes de poder, tendo o médico grande controle sobre a vida do doente (dieta, movimento corporal, ingesta hídrica, remédios e sua via de aplicação) (CUNHA, 2005). Os médicos se formam nesse ambiente, sendo seu imaginário, inconsciente e saber tácito ali moldados. Ao sair do hospital, tendem a reproduzir essas relaçôes autoritárias e uma comunicação unidirecional (TESSER, 2009): o quinto movimento não raro tende a resumir-se a "informar o diagnóstico", e o sexto, a "prescrever o tratamento". Obviamente, isso é um óbice à produção da eficácia simbólica e específica no contexto comunitário.

Há ainda outro obstáculo de origem eminentemente científica: a promessa de eficácia específica derivada da elucidação dos mecanismos da doença e da intervenção material sobre eles certamente "alimentou e alimenta a crença (dificilmente assumida) de que se poderia prescindir do nebuloso emaranhado psicossocial da relação curador-doente" (TESSER, 2009, p. 278).

As dificuldades nos dois últimos movimentos citados são os maiores geradores de litígios, quando esses ocorrem no cuidado médico. Os principais motivos de abertura de processos (71\%) são conflitos na comunicação e não problemas de competência clínica (PENDLETON et al., 2007).

Existem propostas de reconstrução do treinamento clínico dos médicos, nascidas na medicina de família e comunidade, enfatizando o desenvolvimento de habilidades de comunicação (PENDLETON et al., 2007), de que são exemplos o "Método Clínico 
Centrado na Pessoa" (STEWART et al., 2010; MCWHINEY, 2010), canadense, e o método Calgary-Cambridge modificado (KURTZ et al., 2003), usado no treinamento dos general practioners ingleses. No Brasil, há discussôes e propostas sobre o tema na Saúde Coletiva, como a clínica ampliada (CAMPOS, 2003; CUNHA, 2005) e as discussôes sobre humanização e integralidade do cuidado (ANEAS; AYRES, 2011; AYRES, 2001; 2004a; 2004b; 2007; PINHEIRO; MATTOS, 2001; 2003; 2004).

Quanto à construção/operacionalização do plano terapêutico, os problemas que mais parecem se destacar são os comunicacionais e de adequação do tratamento proposto às singularidades sociais e subjetivas dos usuários, reforçados pelo autoritarismo e tendência de padronizaçáo de terapêuticas acima mencionadas, além dos danos iatrogênicos oriundos da farmacoterapia, o recurso mais usado (ALMEIDA, 2002, CAMARGO JR., 2003). Um tratamento requer esclarecimentos e orientaçôes sobre evoluçôes possíveis, sinais de alarme para complicações, efeitos iatrogênicos, possibilidades de retorno ou comunicação em caso de dúvida e medidas em caso de piora. Estudos mostram que doentes apreciam participar das decisôes terapêuticas na biomedicina, e ficam mais satisfeitos quando são convidados a essa participação (STEWART, 2010).

Finalizando este comentário sobre aspectos críticos da biomedicina, podemos considerar que sua tradição hipertrofiou, na subcultura profissional, a investigação (via exames complementares) e a elaboração diagnóstica centrada em doenças e subvalorizou tendencialmente a escuta, a socialização da interpretação e a construção consensuada do plano de manejo. Com isso, dificultou a construção de sua eficácia simbólica e específica, facilitando a multiplicação de iatrogenias oriundas do abuso dos exames complementares, dos fármacos e de problemas de comunicação. Há décadas isso é reconhecido e esforços reiteradamente vêm sendo considerados necessários para superar tais dificuldades, para que essa RM e sua tradição orientem satisfatoriamente um "bom cuidado" médico.

\section{Aplicação em pesquisas}

Nossa categorização permite análises de práticas clínicas ao proporcionar um "zoom" em cada um dos seis movimentos constitucionais dos encontros clínicos. Eles iluminam diferentes aspectos dessas interaçōes complexas e seu saber-fazer. Através deles, as RMs podem ser analisadas em si mesmas: um ato clínico ou um conjunto deles, de um ou vários terapeutas. A categorização permite comparar as 
proposiçóes normativas da RM, se conhecidas ("como deve ser"), com o seu exercício concreto ("como é"), o que pode contribuir para seu ensino. Também facilita estudos comparativos entre profissionais, escolas ou especialidades dentro de uma RM.

Outra potencialidade é seu uso para investigaçóes comparativas entre RMs diferentes, cuja atuação pode ser paralela ou articulada nos mesmos doentes, o que é cada vez mais comum em um mundo que tende ao pluralismo nos cuidados em saúde (HELMAN, 2009). Avançamos algumas ideias e hipóteses nesse sentido.

A categoria RM é uma plataforma de análise compreensiva e comparativa de sistemas médicos complexos, num plano geral de sua descrição através das suas dimensóes constitutivas, que inclui a biomedicina sem partir dela nem a ela aderir. Podemos agregar esta plataforma à nossa categorização, potencializando-a. Com isso, a categorização é amplificada no seu potencial compreensivo, analítico e comparativo, ao mesmo tempo que contribui para operacionalizar investigaçóes das RMs com foco na sua ação clínica vista por dentro. Os seis movimentos dos encontros clínicos relacionam-se, senão com todas as dimensōes das RMs, ao menos com algumas delas, conforme ilustrado na Figura 3.

Figura 3. Relaçóes/influências das dimensôes de uma RM com/sobre os movimentos dos encontros clínicos dos curadores a ela afiliados

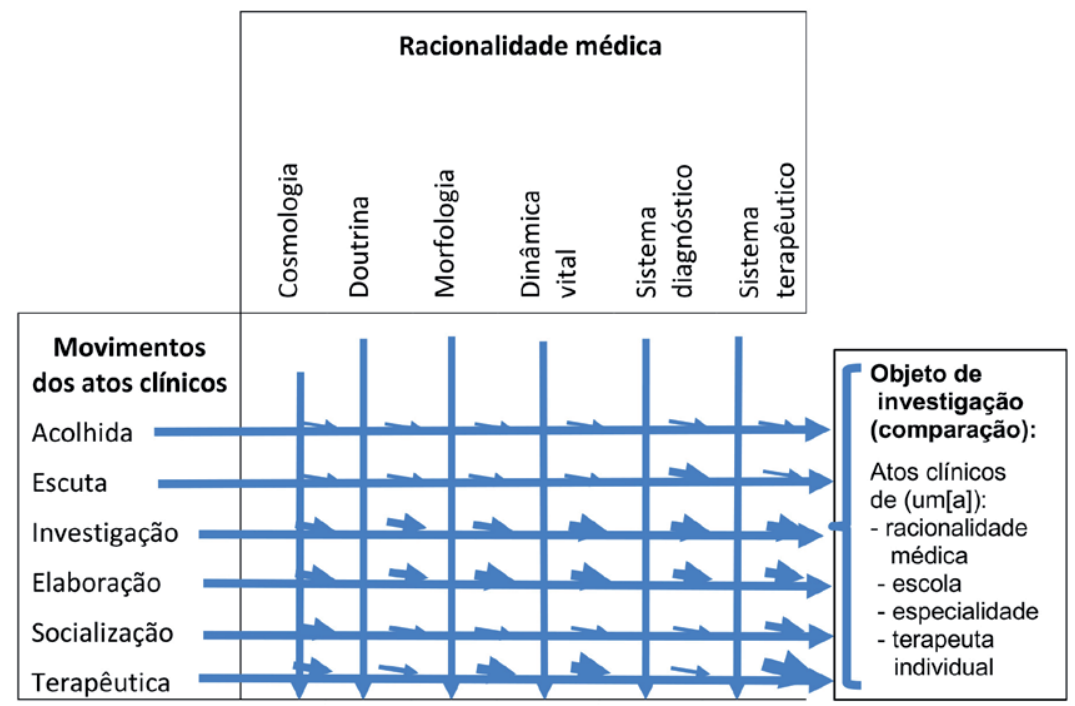

Legenda: as espessuras das setas pequenas indicam a intensidade da correlação no caso da biomedicina (apenas ilustrativo).

Fonte: elaborada pelos autores. 
As relaçóes entre os componentes do ato clínico e as dimensóes da RM nele envolvida podem ser investigadas e descritas teórica e empiricamente. Também as fortalezas, os limites e os aspectos problemáticos dos encontros clínicos podem ser focados em estudos específicos. Tais análises podem contribuir para uma melhor compreensão dos cuidados em distintas RMs. Exemplificando, as consideraçôes gerais acima sobre a biomedicina poderiam ser aprofundadas por análises dos componentes dos atos clínicos à luz das dimensóes da sua RM.

Cada movimento dos encontros clínicos provavelmente é influenciado diferencialmente pelas dimensôes da RM envolvida. A uma primeira visada, como se nota na Figura 3, os movimentos mais relacionados com a produção de saber (investigação, elaboração da interpretação e da terapêutica) sofrem maior influência das dimensóes "teóricas" e abstratas das racionalidades (cosmologia, doutrina, dinâmica vital, morfologia), mas também de seu sistema terapêutico, dado o pragmatismo inerente à atividade curadora, que tende a conectar a elaboração diagnóstica às possibilidades de ação. Já os componentes mais "relacionais", como a acolhida, a escuta, a socialização da elaboração e do plano terapêutico, são mais influenciados pelas tradiçóes práticas, saberes tácitos, atitudes e valores preferenciais da RM e de seus praticantes, desenvolvidos na iniciação, configurando certo estilo e técnica de relacionamento clínico, construídos historicamente e contextualmente reconstruídos.

Em outras palavras, os componentes dos encontros clínicos com suas dimensôes da RM mais associadas distribuem-se desigualmente pelas duas formas de conhecimento-ação presentes nas RMs, com lógicas próprias: uma primeira parte com ambição e tendência analítica, mais "teórica" e "racional", centrada no saber; e outra parte baseada na intuição, observação empírica de casos singulares, sintética, intuitiva, artística, expressa e centrada no fazer, no produzir tratamentos a cada caso, portadora de um saber-(fazer) historicamente construído (LUZ, 2000, p. 184). A esse respeito, uma visão geral sobre a biomedicina encontra-se em Camargo Jr. (2003).

Nossa categorização dos encontros clínicos também prepara o terreno para aproximação de outro tema complexo: a avaliação dos seus resultados. Ou seja, a construção da sua eficácia geral, simbólica (ou inespecífica, mais genericamente) e específica (supostamente), associadas. De um ponto de vista pragmático, social, do doente e do sistema de saúde, importa muito se o tratamento funcionou "bem", se foi efetivo. Na comunidade científica, é consenso que a efetividade, a capacidade de "bom" cuidado e cura na vida "real", supóe eficácia, êxito em ambiente de pesquisa 
científica. Esta eficácia, por hipótese, resultará da "suficiente, correta e exitosa" coerência e articulação das dimensôes das RMs com os seis movimentos dos atos clínicos realizados com expertise por seus terapeutas. Para o estabelecimento desse êxito (avaliação da eficácia), a versão do doente sobre sua melhora é determinante e crucial, deve ser levada em conta e remete a uma discussão impossível de tratar aqui.

A avaliação da eficácia simbólica é facilitada pela nossa categorização, associada com as dimensôes das RMs, pela sua própria construção. A investigação da eficácia específica foi também contemplada através da reserva de espaço descritivo-analítico para a ação dos saberes e das técnicas da RM mobilizados pelo curador na elaboração da interpretação e da terapêutica. Nesta última, estão envolvidas a produção da terapêutica e sua descrição através de açôes cognitivas e concretas (supostamente) específicas, ambas articuladas com os outros movimentos e as dimensóes da RM. O resultado do conjunto dessas açóes no doente pode ser avaliado, e parâmetros para essa avaliação devem ser selecionados.

Os processos cognitivos e operativos produtores da ação terapêutica em sua dimensão (supostamente) específica podem ser desdobrados e investigados a partir da matriz categorial apresentada associada com as dimensōes das RMs, operadas em estratégias investigativas e conceituais específicas, em casos peculiares.

As RMs fornecem parâmetros para avaliação das açôes terapêuticas na sua própria perspectiva, que são, via de regra, os mesmos usados pelos seus terapeutas para a produçáo das interpretaçôes (diagnoses) e reavaliaçáo dos doentes. Para avaliar comparativamente a eficácia de açôes de RMs diferentes, vislumbramos algumas possibilidades e necessidades (impossíveis de desenvolver aqui): fazê-las dialogar, traduzindo parâmetros de uma para outra de forma mutuamente aceitável (consensuar parâmetros comuns 'traduzíveis'); criar parâmetros equidistantes das RMs para situaçôes, saberes e critérios incomensuráveis e intraduzíveis (criar ou eleger parâmetros independentes das RMs, no que os usuários/doentes certamente têm papel crucial); eleger alguma(s) RM(s) como fornecedora(s) de parâmetros em função de situaçôes especiais consensuadas (por exemplo: gravidade e ou urgência; incomensurabilidade e intraduzibilidade de parâmetros inacessíveis ao usuário etc.); combinar as anteriores na construção de jurisprudência social e institucional para mediação e decisão nesses casos e em outros.

Este é um terreno relativamente inexplorado, dado que a biomedicina tem sido a única RM usada no Ocidente como referência para esse fim. São necessárias 
mediaçôes conceituais e estratégias metodológicas adicionais para viabilizar comparaçôes entre a eficácia de ações clínicas de distintas RMs, para o que esperamos contribuir em outro momento. ${ }^{1}$

\section{Agradecimentos}

A Leandro David Wenceslau, pelos comentários críticos e sugestôes.

\section{Referências}

ALMEIDA, E.L.V. As Razóes da Terapêutica: empirismo e racionalismo na medicina. Niterói: EDUFF, 2002.

ANEAS, T.V.; AYRES, J.R.C.M. Significados e sentidos das práticas de saúde: a ontologia fundamental e a reconstrução do cuidado em saúde. Interface. Botucatu, v. 15, n. 38, p. 651662, 2011.

AYRES, J.R.C.M. Cuidado e reconstrução das práticas de Saúde. Interface. Botucatu, v. 8, n. 14, p. 73-92, 2004 a.

O cuidado, os modos de ser (do) humano e as práticas de saúde. Saúde Soc., v. 13, n. 3. p. 16-29, $2004 \mathrm{~b}$.

$72,2001$.

Sujeito, intersubjetividade e práticas de saúde. Ciênc. Saúde Colet., v. 6, n. 1. p. 63-

. Uma concepção hermenêutica de saúde. Physis. Rio de Janeiro, v. 17, n. 1, p. 43-62, 2007.

BARROS, N.F. A construção da Medicina Integrativa: um desafio para o campo da saúde. São Paulo: Hucitec, 2008.

BECKMAN, H.B.; FRANKEL, R.M. The effect of physician behaviour on the collection of data. Annals of Internal Medicine, v. 101, n. 5, p. 692-696, 1984. doi: 10.7326/0003-4819101-5-692.

BONET, O. Do que estamos falando? Eficácia simbólica, metáforas e o "espaço entre". In: TAVARES, F.; BASSSI, F. (Orgs.). Para além da eficácia simbólica: estudos em ritual, religião e saúde. Salvador: EDUFBA, 2012, p. 101-120.

CARRIÓ, F.B. Entrevista clínica: habilidades de comunicação para profissionais de saúde. Porto Alegre: Editora Artmed, 2012.

BRASIL. Ministério da Saúde. Secretaria-Executiva. Núcleo Técnico da Política Nacional de Humanização. HumanizaSUS: Política Nacional de Humanização: a humanização como eixo norteador das práticas de atenção e gestão em todas as instâncias do SUS. Brasília: Ministério da Saúde, 2004. 
BYSTAD, M.; BYSTAD, C.; WYNN, R. How can placebo effects best be applied in clinical practice? A narrative review. Psychol Res Behav Manag, v. 8, p. 8:41-5, 2015. doi: http://dx.doi. org/10.2147/PRBM.S75670

CAMARGO JR., K.R. Biomedicina, ciência \& saber: uma abordagem crítica. São Paulo: Hucitec, 2003.

CAMPOS, G.W.S. Saúde Paideia. São Paulo: Hucitec, 2003. 185p.

CARRIÓ, F.B. Entrevista clínica: habilidades de comunicação para profissionais de saúde. Porto Alegre: Artmed Editora, 2009.

CUNHA, G.T. A construção da clínica ampliada na atenção básica. São Paulo: Hucitec, 2005.

DALMASO, A.S.D. Estruturação e transformação da prática médica: técnica e ciência na segunda metade do século XX. 1998. Tese (Doutorado em Medicina Preventiva e Social) - Faculdade de Medicina, Universidade de São Paulo (USP), São Paulo, 1998.

DECETY, J.; FOTOPOULOU, A. Why empathy has a beneficial impact on others in medicine: unifying theories. Front. Behav. Neurosci. Lausanne (Switzerland), v. 8, art 457, 2014. doi: 10.3389/fnbeh.2014.00457.

DI BLASI, Z. et al. Influence of context effects on health outcomes: a systematic review. Lancet, v. 357, n. 9.258, p. 757-62, 2001.

FLECK, L. Gênese e desenvolvimento de um fato científico. Belo Horizonte: Fabrefactun, 2010.

FOUCAULT, M. O Nascimento da Clínica. 6. ed. Rio de Janeiro: Ed. Forense Universitária, 2004.

FRIEDMAN, D.S. et al. Doctor-patient communication in glaucoma care: analysis of videotaped encounters in community-based office practice. Ophthalmology, v. 116, n. 12, p. 2.277-85, 2009. doi: 10.1016/j.ophtha.2009.04.052

GASK, L.; USHERWOOD, T. The Consultation. BMJ, v. 324, p. 1567-9, 2002.

GREENHALGH, T.; HOWICK, J.; MASKREY, N. Evidence based medicine: a movement in crisis? BMJ, v. 348, p. g3725, 2014, doi: 10.1136/bmj.g3725

GUIMARĀES, M.B.L. Intuição, pensamento e ação na clínica. Interface. Botucatu, v. 9, n. 17, p. 317-332, 2005.

HAIDET, P.; PATERNITI, D.A. Building a history rather than taking one: A perspective on information sharing during the medical interview. Archives of Internal Medicine, v. 163, n. 10, p. 1.134-1.140, 2003.

HARRISON S. Co-Optation, commodification and the medical model: governing UK medicine since 1991. Public Administration, v. 87, n. 2, p. 184-97, 2009.

HARRISON, S.; MORAN, M.; WOOD, B. Policy emergence and policy convergence: the case of "scientific-bureaucratic medicine" in the United States and United Kingdom. The British Journal of Politics and International Relations, v. 4, n. 1, p. 1-24, 2002. 
HELMAN, C.G. Cultura, saúde e doença. 5. ed. Porto Alegre: Artmed, 2009. 431 p.

KAPTCHUK, T.J.; EDWARDS, R.A.; EISENBERG, D.M. Medicina complementar: eficácia além do efeito placebo. In: ERNST. E. (Ed.). Medicina complementar: uma avaliaçâo objetiva. São Paulo: Manole, 2001, p. 39-64.

KLOETZEL, K. Medicina Ambulatorial: princípios básicos. São Paulo: EPU, 1999.

KUHN, T.S. A estrutura das revoluçóes científicas. 12. ed. São Paulo: Perspectiva, 2013.

KURTZ, S.M. et al. Marrying Content and process in clinical method teaching: enhancing the Calgary-Cambridge guides. Academic Medicine, v. 78, n. 8, p. 802-809, 2003.

LATOUR, B. Jamais fomos modernos: ensaios de antropologia simétrica. 2. ed. Rio de Janeiro: Ed. 34, 2009.

. Reagregando o social: uma introdução à teoria do ator-rede. Salvador: Edufba, 2012.

LEVINSON, W. et al. Physician-patient communication. The relationship with malpractice claims among primary care physicians and surgeons. JAMA, v. 277, n. 7, p. 553-9.

LÉVI-STRAUSS C. Antropologia estrutural. Rio de Janeiro: Ed. Tempo Brasileiro, 1976.

LUZ, M.T. Cultura contemporânea e medicinas alternativas: novos paradigmas em sáude no fim do século XX. Physis: Revista de Saúde Coletiva. Rio de Janeiro, v. 15, supl., p. 145-176, 2005.

- Medicina e racionalidades médicas: estudo comparativo da medicina ocidental contemporânea, homeopática, chinesa e ayurvédica. In: CANESQUI, A.M. (Org.). Ciências Sociais e saúde para o ensino médico. São Paulo: Hucitec/Fapesp, 2000, p. 181-200.

LUZ, M.T.; BARROS, N.F. (Orgs.). Racionalidades médicas e práticas integrativas em saúde: estudos teóricos e empíricos. Rio de Janeiro: UERJ/IMS/LAPPIS, 2012.

LUZ, M.T.; CAMARGO JR., K.R. A comparative Study of medical rationatilies. Curare Journal of ethnomedicine. Berlin, v. 12, p. 47-58, 1997.

MALTERUD, K. et al. Understanding medical symptoms: a conceptual review and analysis. Theor Med Bioeth Theoretical Medicine and Bioethics, v. 36, n. 411, 2015. https://doi.org/10.1007/ s11017-015-9347-3

MARVEL, M.K. et al. Soliciting the patient's agenda: have we improved? JAMA, v. 281, n. 3, p. 283-7, 1999.

MCDONALD, D.D.; FEDO, J. Older Adults' Pain Communication: The Effect of Interruption. Pain Manag Nurs., v. 10, n. 3, p. 149-153, 2009.

MCWHINNEY, I.R. Manual de medicina de família e comunidade. 3. ed. Porto Alegre: Artmed, 2010.

MORAES, M. A ciência como rede de atores: ressonâncias filosóficas. Hist. Ciênc. SaúdeManguinhos, v. 11, n. 2, p. 321-33, 2004. 
NASCIMENTO, M.C. (Org.). A duas faces da montanha: estudos sobre medicina chinesa e acupuntura. São Paulo: Hucitec, 2006.

NASCIMENTO, M.C. et al. A categoria racionalidade médica e uma nova epistemologia em saúde. Ciênc. Saúde Coletiva, v. 18, n. 12, p. 3.595-3.604, 2013.

NASCIMENTO, M.C.; NOGUEIRA, M.I. (Orgs.). Intercâmbio solidário de saberes em saúde: racionalidades médicas e práticas integrativas e complementares. São Paulo: Hucitec, 2013.

NORMAN, A.H.; TESSER, C.D. Prevenção quaternária na atenção primária à saúde: uma necessidade do Sistema Único de Saúde. Cad. Saúde Pública, v. 25, n. 9, p. 2.012-2.020, 2009.

ORGANIZACIÓN MUNDIAL DE LA SALUD. Estrategia de la OMS sobre medicina tradicional 2014-2023. Genebra: OMS, 2013.

PENDLETON D, S.T.; TATE, P.; HAVELOCK, P. The new Consultation: developing doctorpatient communication. Oxford: Oxford University Press, 2007.

PETERSON, M.C. et al. Contributions of the history, physical examination, and laboratory investigation in making medical diagnoses. West J Med., v. 156, n. 2, p. 163-5, 1992.

PINHEIRO, R.; MATTOS, R.A. (Orgs.) Construção da integralidade: cotidiano, saberes e práticas em saúde. Rio de Janeiro: UERJ/IMS/Abrasco, 2003.

. Cuidado: as fronteiras da Integralidade. São Paulo: Hucitec, 2004.

. Os sentidos da integralidade na atenção e no cuidado à saúde. Rio de Janeiro: UERJ, IMS:

Abrasco, 2001.

PRICE, D.D.; FLINNISS, D.G.; BENEDETTI, F. A Comprehensive Review of the Placebo Effect: Recent Advances and Current Thought. Annu. Rev. Psychol., v. 59, n. 1, p. 565-590, 2008. Disponível em: <http://dx.doi.org/10.1146/annurev.psych.59.113006.095941>. Acesso em: 7 maio 2015.

QUEIROZ, M.J. SOAP Revisitado. Rev Port Clin Geral, v. 25, n. 2, p. 221-7, 2009.

QUINTANEIRO, T.; DE OLIVEIRA-BARBOSA, M.L.; DE OLIVEIRA, M.G. Um toque de clássicos: Durkheim, Marx e Weber. 2. ed. Belo Horizonte: Editora UFMG, 2003.

RABINOWITZ, I. et al. Length of patient's monologue, rate of completion, and relation to other components of the clinical encounter: observational intervention study in primary care. $B M J$, v. 328, n. 7.438, p. 501-502, 2004. doi: http://dx.doi.org/10.1136/bmj.328.7438.501

RHOADES, D.R. et al. Speaking and interruptions during primary care office visits. Fam Med., v. 33, n. 7, p. 528-32, 2001.

RIBEIRO, D. O povo brasileiro: a formação e o sentido do Brasil. São Paulo: Companhia das Letras, 1995.

ROSEMBAUM, P. Entre arte e ciência: fundamentos hermenêuticos da medicina homeopática. São Paulo, Hucitec, 2006. 
ROSHAN, M.; RAO, A.P. A study on relative contributions of the history, physical examination and investigations in making medical diagnosis. J Assoc Physicians India., v. 48, n. 8, p. 771-775, 2000.

SALLES, S.A.C. Aplicação do princípio dos semelhantes e a matéria médica. In: ROSENBAUM, P. (Org.). Fundamentos de Homeopatia para estudantes de Medicina e de Ciências da Saúde. São Paulo: Roca, 2002.

SCHRAIBER, L.B. O médico e suas interaçôes: a crise dos vínculos de confiança. São Paulo: Hucitec, 2008.

SCHULBERG, H.C.; BURNS, B.J. Mental disorders in primary care: epidemiologic, diagnostic, and treatment research directions. Gen Hosp Psychiatry, v. 10, n. 2, p. 79-87, 1988.

SILVERMAN, J.; KURTZ, S.; DRAPER, J. Skills for communicating with patients. Boca Raton (USA): CRC Press, 2016.

SIMS, T.; TSAI, J.L.Patients respond more positively to physicians who focus on their ideal affect. Emotion, v. 15, n. 3, p. 303-18, 2015.

STARFIELD, B. et al. The influence of patient-practitioner agreement on outcome of care. Am J Public Health, v.71, n.2, p.127-131, 1981.

STEWART, M. et al. Medicina centrada na pessoa: transformando o método clínico. Porto Alegre: Artmed, 2010.

STEWART, M.A.; MCWHINNEY, I.R.; BUCK, C.W. The doctor- patient relationship and its effect upon outcome. J R Coll Gen Practioners, v. 29, n. 199, p. 77-82, 1979.

TAVARES, F.; BASSI, F. (Orgs.). Para além da eficácia simbólica: estudos em ritual, religião e saúde. Salvador: EDUFBA, 2012.

TESSER, C. D. Produção de saber, racionalidades médicas e cuidado: ideias iniciais. In: NASCIMENTO, M.C.; NOGUEIRA, M.I. (Orgs.). Intercâmbio solidário de saberes em saúde: racionalidades médicas e práticas integrativas e complementares. São Paulo: Hucitec, 2013, p. 80-105.

. Três considerações sobre a "má medicina". Interface. Botucatu, v. 13, n. 31, p. 273286, 2009.

WEBER, M. A ética protestante e o espirito do capitalismo. São Paulo: Companhia das Letras, 2004.

\section{Nota}

${ }^{1}$ C.D. Tesser foi responsável pela concepção, elaboração da primeira versão, revisões intermediárias e redação da versão final. M.T. Luz participou da discussão dos conteúdos, revisão conceitual, revisôes intermediárias e revisão crítica da versão final. 


\section{Abstract}

An analytical categorization for the study and comparison of clinical practices in distinct medical rationalities

This article presents an analytical categorization of clinical encounters for comparative equidistant investigations of clinical practice in different medical systems. This categorization was conceived as an ideal Weberian type, guided by Levi-Strauss's dynamics of symbolic effectiveness. We conceptualized six constituent movements of clinical encounters: (1) user's acceptance; (2) demand listening; (3) problem investigation; (4) diagnosis elaboration and interpretation; (5) socialization of interpretation; and (6) therapy elaboration, agreement and implementation. These constituent movements can be associated with Madel Luz's medical rationality dimensions (cosmology, doctrine, physiology, morphology, diagnostic and therapeutic systems), allowing the description, analysis and comparison of various clinical practices, guided by one or more medical rationalities. Therefore, this analytical instrument could facilitate the investigation and understanding of clinical practices within different medical systems, contributing to both comparability of different medical practices and to its general effectiveness.

> Keywords: traditional medicine; alternative medicine; methodology. 